\title{
UM CONVITE À REFLEXÃO: DESIGN E A INTERAÇÃO NO MUSEU
}

Rosana Ferreira Alexandre

Pontifícia Católica do Rio de Janeiro

rosanafalexandre@gmail.com

Luiza Novaes

Pontifícia Católica do Rio de Janeiro

Inovaes@puc-rio.br

Jackeline Farbiarz

Pontifícia Católica do Rio de Janeiro

jackeline@puc-rio.br

Resumo: Esse artigo pretende discutir possibilidades de inserção do design no museu, em um momento em que a instituição encara novos desafios pela consolidação de sua função social e diversificação do seu público. Seguindo a ótica dos wicked problems, usualmente relacionados ao campo do design, aborda o aspecto indeterminado e interdisciplinar dos problemas e sua importância no processo criativo, e descreve dois casos práticos. Se apropria do conceito "à deriva", proposto pelo Movimento Situacionista e conclui que o design, conceituado aqui como uma disciplina à deriva, complexa, entre-fronteiras e entre-limites, pode ser uma possibilidade para as instituições museológicas se vincularem com o público, neste caso especificamente o infantil.

Palavras-chave: museu, público, interação, interdisciplinaridade, wicked problems.

Abstract: This article discusses the possibilities of design integration in the museum, at a time when the institution faces new challenges for the consolidation of its social function and diversification of the audience. Following the perspective of wicked problems, usually related to the field of design, it discusses the indeterminate and interdisciplinary aspects of the problems and their importance in the creative process, and describes two case studies. It uses the concept of dérive proposed by the Situationist Theory and concludes that the design, regarded here as a discipline dérive, complex, between borders and between limits, may be a possibility for the museums to link with the public, in this case specifically the children.

Keywords: museum, public, interaction, interdisciplinarity, wicked problems. 


\section{INTRODUÇÃO}

A associação entre os campos do design e da museologia remete-nos principalmente a dois eixos de ação específicos: o da elaboração do espaço em si, abrangendo o projeto museográfico bem como a sinalização dos espaços; e o das estratégias comunicativas, envolvendo, dentre outras, a identidade visual do museu, a comunicação visual das exposições, a confecção de impressos, catálogos e livros, e o desenvolvimento de produtos baseados nos acervos. Apesar de considerarmos estes eixos de grande importância, eles não se configuram como o centro da presente pesquisa, que se propõe a refletir sobre que design é esse que possibilita o envolvimento/acolhimento do público no museu e que possibilidades de interação podemos imaginar para esse contexto.

Começamos a reflexão discutindo conceitos de design e percebemos que muitas são as definições encontradas. Para explorar as questões pertinentes à atividade do profissional da área, buscamos um paralelo com a situação "à deriva", proposta pelos situacionistas (Debord, 1972). Embarcamos neste caminho que nos leva à complexidade, à indeterminação e ao mesmo tempo à liberdade para criar neste contexto. Enfocamos a formulação dos wicked problems para entender a imprevisibilidade e o campo interdisciplinar do design.

Por fim, optamos por analisar dois casos práticos em que o design colaborou com museus. Exploramos a necessidade destas instituições em procurar novas abordagens em diferentes áreas para tentar estabelecer relações de interação com a sociedade.

\section{CONCEITUANDO DESIGN}

\subsection{Pensar o design "à deriva"}

O conceito que explora o lugar do design como "à deriva" requer esclarecimentos. Liderado por Guy Debord, o movimento da Internacional Situacionista (IS) foi criado com o intuito de contrariar a noção de cidade/cultura espetacular, a alienação e a passividade da população. Entre outras coisas, propunha formas de apropriação e percepção dos campos artístico e urbanístico segundo uma nova perspectiva: o olhar da vida cotidiana e o lado subjetivo de vivê-lo.

Entendida como geografia afetiva, em que se anda pela cidade para se chegar a uma nova forma de apreensão do espaço, estar "à deriva" não é sinônimo de estar perdido ou sem rumo, mas sim de dar espaço para a liberdade. À deriva, de certa forma, tem um objetivo, uma meta, compreende uma busca, um processo de descoberta, mesmo que, ao início do percurso, não se saiba exatamente o que iremos encontrar ${ }^{1}$. É assim também que Japiassú entende a epistemologia. O conhecimento, para o filósofo, é um processo e não um estado.

(...) Trata-se de uma disciplina permitindo-nos submeter a prática científica a uma reflexão que, diferentemente da filosofia clássica da ciência, aplica-se, não à ciência feita, acabada, verdadeira, de que deveríamos fornecer todos os seus títulos de legitimidade, mas às

\footnotetext{
1 Notas da aula "Desenho e levantamento do lugar" ministrada por José Marques no âmbito do Mestrado em Arte e Design para o Espaço Público na Universidade do Porto em 2007.
} 
ciências em vias de se fazerem, em seu desenvolvimento histórico, vale dizer, em sua processualidade. (Japiassú, 1981, p. 96).

Pois bem, é assim, compactuando com o conceito "à deriva" que tentamos aprofundar uma reflexão sobre design. Afinal, seu campo de atuação é aberto, amplo, tornando complexo o ato de definição, assim como é a própria prática do design.

A busca por uma definição para o design, em que consiste e como se caracteriza a atividade, tem sido alvo de muitos estudiosos. Por sua característica híbrida e difusa, de acordo com a perspectiva escolhida, diferentes abordagens são privilegiadas. Existem definições que buscam compreender o design com o foco na materialização de produtos, outras como solucionador de problemas. Tem as que pensam o design como uma dualidade entre verbo e substantivo, as que caracterizam o termo como uma disciplina em contraponto a uma ciência e as que entendem que design é mais um processo do que a configuração em si de objetos.

Debord ao propor a criação de situações como forma de vivenciar um espaço utiliza como método a psicogeografia e a errância como prática. A errância, nesse caso entendida como:

(...) uma forma curiosa, atenta, porém aberta, de fazer alguma exploração. Refere-se a uma dimensão construtiva, a qual implica uma relação múltipla, que ora considera um aspecto ora considera outro, ora observa forma, ora o conteúdo, ora o tema, ora as imagens, sabendo que tudo isso faz parte de um mesmo todo. (Macedo,Petty e Passos, 2005, p. 21)

Pois esse aspecto errante, que insere o múltiplo e o multifacetado proposto pelos situacionistas pode relacionar-se também com os tipos de problemas com os quais o design lida frequentemente no seu cotidiano e esse pode ser um caminho para se entender o amplo e intenso diálogo que o design estabelece com as demais disciplinas.

\subsection{Pensar o design na relação com Problemas complexos e indeterminados}

Justamente por estar "à deriva" e por fazer uso da errância como prática, outra forma de conceituarmos design pode partir de ações focadas em problemas complexos e indeterminados. Em 1973 os professores Horst Rittel e Melvin Webber escreveram um artigo em que formulavam um novo entendimento para problemas de ordem social. No texto "Dilemmas in a general theory of plannig", os autores argumentam que estes problemas de ordem social não podem ser pensados e nem solucionados como os de natureza científica, como seriam os de engenharia, por exemplo. Propõem então uma nova categorização que denominaram de "wicked problems", traduzindo livremente podem ser entendidos como problemas complexos ou capciosos. (Rittel e Webber, 1973, p. 160). Essa formulação surge em contraponto à metodologia de projeto linear que, seguindo um passo-a-passo ou uma sequência de fases, se divide basicamente em duas etapas distintas, que são a identificação do problema e a solução do mesmo.

Para os autores, estes problemas de ordem social devem ser vistos como complexos por se apresentarem como situações que não têm uma formulação definida e muito menos um fim alcançável. Devem, portanto, ser encarados como um processo contínuo, como questões a serem (re)solucionadas. Deste modo, problemas desta 
natureza não correspondem a uma resposta certa ou errada, conceitos inexistentes nestes tipos de situações. O mais adequado é entender as possíveis soluções como melhores ou piores, ou como satisfatórias ou não. (Rittel e Webber, 1973, p. 163).

Esses tipos de problemas são caracterizados também como situações únicas, pois apesar de em alguns casos apresentarem similaridades entre eles, cada situação tem suas particularidades que devem ser levadas em consideração.

Não se pode entender o problema sem saber sobre o seu contexto, não se pode procurar informações de forma significativa sem a orientação de um conceito de solução, não se pode entender primeiro e depois resolver. (Rittel e Webber, 1973, p. 162).

Ao revisitar as proposições feitas por Rittel e Weber sobre os problemas complexos, o também professor Richard Buchanan aponta algumas considerações importantes. A partir do momento em que se fala de wicked problems pressupõe-se a noção de um pensamento em aberto em que não existe regras para se chegar a uma possível solução, nem testes definitivos para verificar sua eficácia e, que, de acordo com o ângulo de observação uma causa é mais focada que outra.

Chama a atenção também para o fato de que, apesar de ser mais atraente pensar numa metodologia de projeto linear, em que o designer lida com problemas de ordem lógica e que, portanto, as soluções são possíveis de serem calculadas, o mais usual para o campo do design é se deparar com situações complexas. A postura de indeterminação está implícita nos problemas de ordem complexa e é justamente desse espaço "livre", desse intervalo que o designer se apropria para desenvolver o que ainda não existe.

Remetendo-nos novamente aos situacionistas, assim como a influência do cenário é importante na experimentação da cidade, para o designer é importante observar e aceitar a imprevisibilidade em seu trabalho, fruto desta complexidade. Por mais que se tenha uma meta, um destino, durante o percurso surgem escolhas, opções, e virar à direita ou à esquerda na próxima esquina significa criar novas respostas, novos repertórios, que podem ou não ser satisfatórios.

\subsection{Pensar o design nas perspectivas de (in)determinação e (inter)disciplinaridade}

Estando "à deriva", trabalhando na complexidade e indeterminação, o design pode ser conceituado como pertencente a um "entre-fronteiras e entre-limites". 0 design não necessariamente se ocupa de um assunto em particular, mas sim de ter potencial para atuar, pelo menos em teoria, em qualquer campo. (Buchanan, 1992, p. 16). Neste sentido o posicionamento de um campo amplo e pouco demarcado pode ser visto tanto como um empecilho como também como uma peculiaridade, em que a própria falta de limites pode vir a ser uma qualidade para designar esta área.

Seu aspecto interdisciplinar, que em alguns casos mais se aproxima de um discurso vazio, e que por isso mesmo acaba por confundir ainda mais, pode ser entendido como característica de um saber próprio do design. Um saber que tem nas fronteiras flexíveis um campo fértil, pois dialoga constantemente com outras disciplinas. (Couto, 1997)

Nesse sentido, mais interessante do que pensar no design como um campo científico é refletir sobre o design como uma disciplina. Nigel Cross faz essa distinção 
ao falar da diferenciação no modo de agir nos dois casos. Enquanto para a ciência clássica os métodos são fundamentais para se validar resultados e criar regras, para o design a especificação de normas pode ser um empecilho para o processo criativo. (Cross, 2001).

Em síntese, recuperando a questão "Que design é esse?", mencionada na introdução do presente artigo, nossas reflexões nos levam a conceitua-lo como "à deriva, complexo, indeterminado e interdisciplinar". Enfim, como uma disciplina e não uma ciência exata, que, por sua base conceitual está habilitado a contribuir com o envolvimento/acolhimento do público junto aos museus, tendo em vista possibilidades de interação.

\section{CAMINHOS DO DESIGN NO MUSEU}

\subsection{Museu na contemporaneidade}

A vontade de colecionar objetos, de preservar testemunhos de uma época e sociedade é, de certa forma, a origem do que hoje conhecemos como museu. Se inicialmente a visita às coleções era um privilégio de poucos, apenas os homens cultos tinham essa permissão, com o tempo o acesso ao museu se torna direito de todo e qualquer cidadão.

Em meados do século XX a instituição museológica é alvo de críticas; surgem questionamentos em relação à continuidade de práticas conservadoras, focadas nos objetos. $O$ desejo era que a instituição não se preocupasse somente com a posse dos objetos, mas que se relacionasse e se envolvesse com a sociedade, e propusesse uma inter-relação do passado com o presente. Questões como a socialização do conhecimento, democratização dos acervos e aproximação com o público como instituição educativa e, portanto, desencadeadora de uma possível transformação social, tornaram-se frequentes. O rumo tomado pelo campo museológico, em oposição à manutenção tradicional do museu, apontava para uma nova perspectiva de atuação: o objeto existe em razão do homem. $O$ ato de colecionar como fim em si não faz mais sentido, os objetos devem ser entendidos não mais como instâncias congeladas no tempo, mas sim como representações simbólicas que despertam relações, experiências e referências compartilhadas com todos os indivíduos.

Além de colecionar, conservar, estudar, interpretar e expor os testemunhos da sociedade (Noble apud Poulot, 2013, p. 22), ou seja de salvaguarda do patrimônio, o papel do museu foi expandido e novas funções foram acrescidas. A instituição passou a ser responsável pela discussão sobre o que fazer com tais objetos e de que forma estabelecer um diálogo entre esses objetos e o presente, além do debate de como produzir conhecimento. Nesse sentido, Poulot (2013, p. 44) ressalta que “(...) o museu deve conservar elementos do passado e, ao mesmo tempo, conferir-lhe consciência, ou seja, construir uma narrativa, sem reduzir seus visitantes ao silêncio (...)".

Entretanto, o processo de ampliação da visitação ao museu para atender todas as audiências tem sido lento e, com inúmeras dificuldades. Dialogar com toda a população, principalmente com aqueles segmentos que não estão habituados a frequentar estes espaços, não tem sido tarefa fácil, requerendo esforço constante por parte das instituições. Paulo Herkenhoff, diretor cultural do Museu de Arte do Rio (MAR) ressaltou essa questão na inauguração do mesmo. Para ele é preciso refletir sobre "Como receber uma pessoa que cruza esse espaço desconhecido, que para ela é 
uma barreira social, já que ela nem sabe se está vestida corretamente, ela tem medo de se comportar. Isso tudo tem que ser visto com enorme afetividade." (Canônico \& Cypriano, 2013).

Assim, para as instituições culturais que querem ser entendidas como "museus do século $X X^{2}{ }^{21}$ é importante pensar não só na produção de significados, mas também na (re)construção destes, além de criar um diálogo efetivo com todo o tipo de público e não só com aquele que já é frequentador assíduo. Como em qualquer processo, a mudança traz novos desafios, e pede novas abordagens. A aproximação com outras áreas e a absorção de novas ideias é um caminho.

\subsection{A colaboração do design}

A abertura faz o museu repensar sua forma de trabalhar e considerar cada vez mais a busca por equipes que abarquem essa diversidade contemporânea, com grupos heterogêneos. Se a associação com a educação e a comunicação já se mostra estabelecida, no campo do design ainda está em vias de se concretizar. Certamente o museu pode se beneficiar desta aproximação. Para o designer, o trabalho em parceria, em colaboração e interação com outras disciplinas faz parte do seu cotidiano, vide a perspectiva interdisciplinar abordada no tópico 2.3 do presente artigo. Também sugerir soluções para novos problemas, trabalhar em momentos de indeterminação, produzir respostas possíveis para eventos novos e que se redefinem, faz parte da rotina do designer, conforme apresentado nos tópicos 2.1 e 2.2 .

Ao se pensar as relações do design no museu muitas são as possibilidades. $E$ como numa abordagem de um problema complexo, a escolha de ângulo de visão cria a perspectiva a ser enfatizada. Isso foi o que aconteceu, por exemplo, nos projetos desenvolvidos tanto para o Museu de Serralves ${ }^{3}$ quanto para o Museu Casa do Infante 4 , esse último apresentado na dissertação de mestrado intitulada "Porto através do jogo: Uma construção lúdica para o Museu Casa do Infante" (Alexandre, 2009. A seguir, a partir dos dois projetos comentamos os exemplos trabalhados.

A primeira aproximação aconteceu em decorrência de uma parceria do Museu de Arte Contemporânea (Serralves) com a faculdade de Belas Artes da Universidade do Porto, com o intuito de selecionar trabalhos para seu festival anual. O propósito do projeto era estabelecer uma relação concreta com os mais variados visitantes. Especificamente para este projeto a escolha feita foi por crianças de dois a cinco anos que vão ao evento com suas famílias e concentram a visita no jardim do Museu. A concepção do projeto baseou-se numa estrutura modular, composta por quatro módulos triangulares interdependentes, que formavam um grande quebra-cabeça. Suas faces possuíam aberturas distintas para serem combinadas entre si. Ao manipular da maneira que quisessem esses módulos, as crianças criavam uma trajetória lúdica por meio de cheios e vazios, do descobrir e do esconder e por meio da percepção de formas e cores distintas.

\footnotetext{
${ }^{2}$ Museus que se preocupam com aspectos da cultura contemporânea, independentemente de terem sido criados recentemente ou não. (Lara Filho, 2012).

${ }^{3} \mathrm{O}$ projeto em questão, Trajetória lúdica, foi realizado em parceria com a também aluna do Mestrado em Arte e Design para o Espaço Público da Universidade do Porto, Brunna Anchieta, e foi apresentado nos dias 07 e 08 de junho de 2008 durante o Serralves em Festa, evento anual do Museu.

${ }^{4} \mathrm{O}$ projeto Porto através do jogo: uma construção lúdica para o Museu Casa do Infante, é decorrente da parte prática da dissertação e destinado ao público infantil entre os 6 e 11 anos de idade.
} 

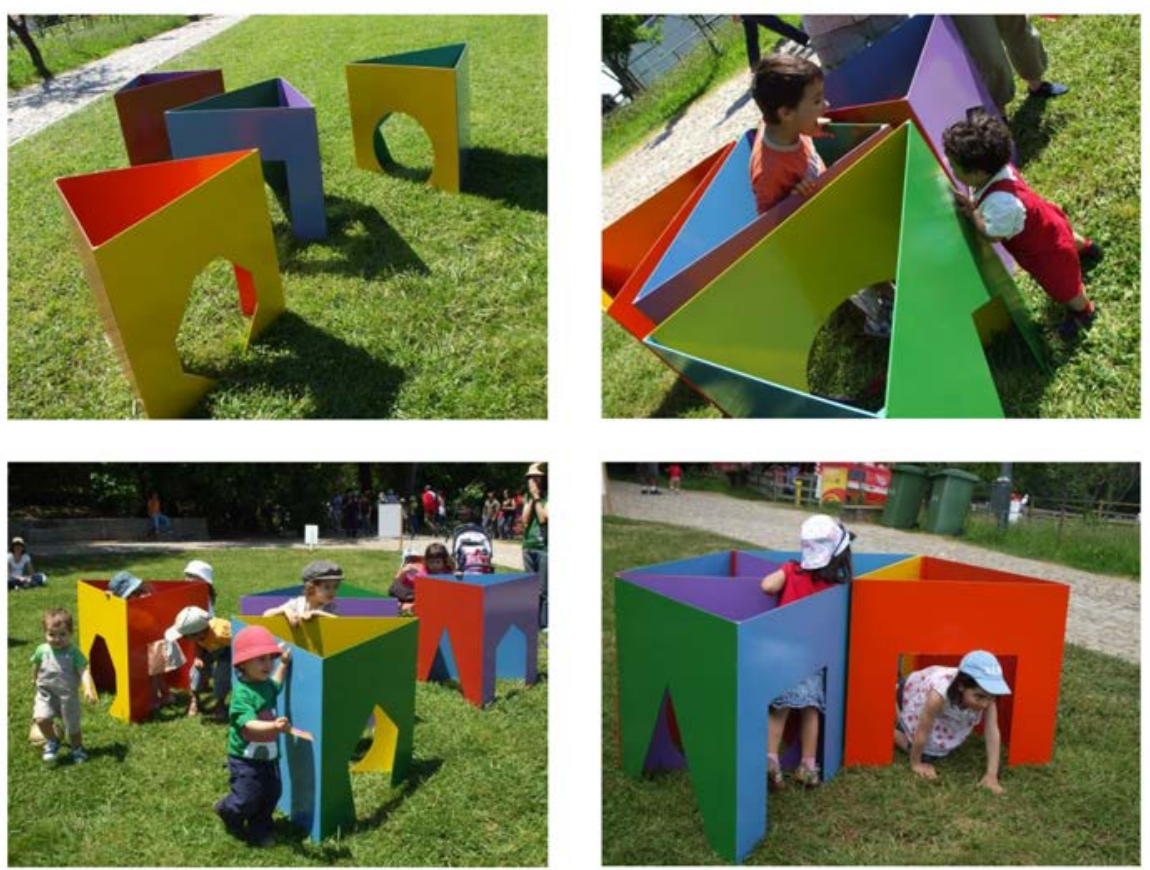

Figura 1: Diversas arrumações e manipulações dos módulos.

Fotos: Brunna Anchieta, Eduardo Massa e Rosana Alexandre.

O segundo caso foi decorrente de uma pesquisa de campo para o desenvolvimento da dissertação. Ao frequentar o espaço como possível objeto de estudo, o núcleo educativo sugeriu que "um olhar de fora" podia ajudar na mediação do seu acervo com o público infantojuvenil. Com o propósito de não só atrair mas também cativar crianças a visitarem o Museu foi desenvolvido um objeto lúdico sob a forma de uma visita divertida pelo acervo. O objeto aqui proposto é também uma possibilidade de descobrir a cidade do Porto, conteúdo expositivo de longa duração da Casa do Infante, como que para se sentirem, mesmo que simbolicamente, parte da cidade: a partir de seus esforços, o Porto aparece e toma vida. A construção simbólica é dividida em três etapas.

A primeira fase funciona como uma "caça ao tesouro" no Museu. O desafio para as crianças é explorar o local em busca de respostas a perguntas contidas em cartas. Estas evocam uma área da Casa do Infante e abordam temas referentes ao acervo da mesma. Através delas, pretendemos despertar o interesse das crianças pelo museu, incitar o aprendizado como uma busca de conhecimentos, em detrimento apenas da memorização de conceitos, além de estimular a socialização e resolução de problemas por meio da dinâmica de grupo. A cada resposta certa, os participantes recebem uma almofada, com o traçado da cidade costurado, para encaixar sobre uma lona, de acordo com as coordenadas correspondentes presentes na mesma. Depois de montadas, as almofadas formam o mapa de parte da cidade, como o tabuleiro de um jogo. 

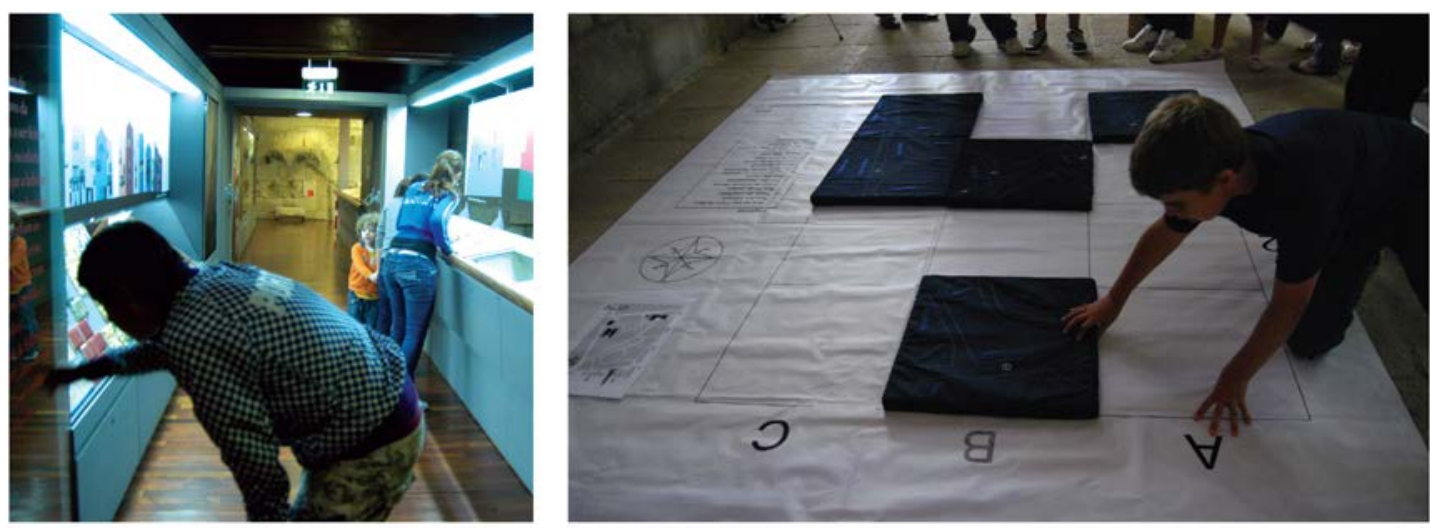

Figuras 2 e 3: A “caça ao tesouro" pelo Museu e a disposição das almofadas sobre a lona. Fotos: Eduardo Massa e Vânia Cunha.

A fase seguinte é realizada através do encaixe, sobre as almofadas já dispostas, dos quarteirões. Estes consistem em almofadas com formas assimétricas e estampa própria, que representa as habitações da cidade. É como um grande quebra-cabeça, mas em que as crianças podem "entrar", pisar e interagir, devido à sua dimensão aumentada e à utilização de tecidos e espuma. Isto permite que os participantes percebam a cidade por outras formas, através do sentar, deitar ou mesmo abraçar. É possível uma exploração não só através das mãos, como de todo o corpo da criança, o que potencializa a experiência sensorial. $O$ encaixe é feito por velcro, e as peças devem ser colocadas de acordo com o formato correspondente pespontado nas almofadas. É também através desta etapa que começamos a trabalhar a tridimensionalidade do mapa, que adquire volume e se torna quase uma maquete da cidade. Este fator permite visualizar e interpretar a cidade através de um somatório de camadas que simulam as construções da mesma.
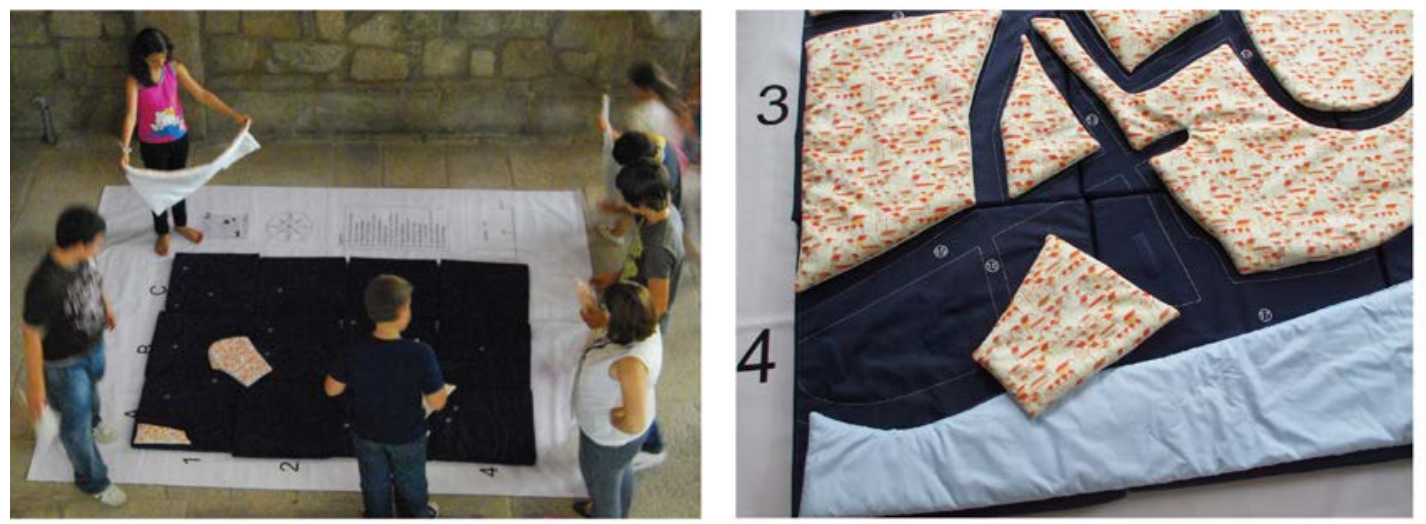

Figuras 4 e 5: Montagem e encaixe dos quarteirões.

Fotos: Eduardo Massa e Vânia Cunha.

A última etapa consiste em construir, tridimensionalmente, monumentos de referência da cidade. Ao todo são sete construções históricas situadas no mapa representado. As crianças recebem um papel apenas com o contorno destas com instruções de corte e colagem. Elas devem personalizá-las conforme queiram e depois monta-las como grandes peças de um jogo de tabuleiro. Além de estimular a 
imaginação e interpretação, a espacialidade é trabalhada pelo processo de montagem dos monumentos. Posteriormente devem ser localizados no mapa e colocados em seus devidos locais.
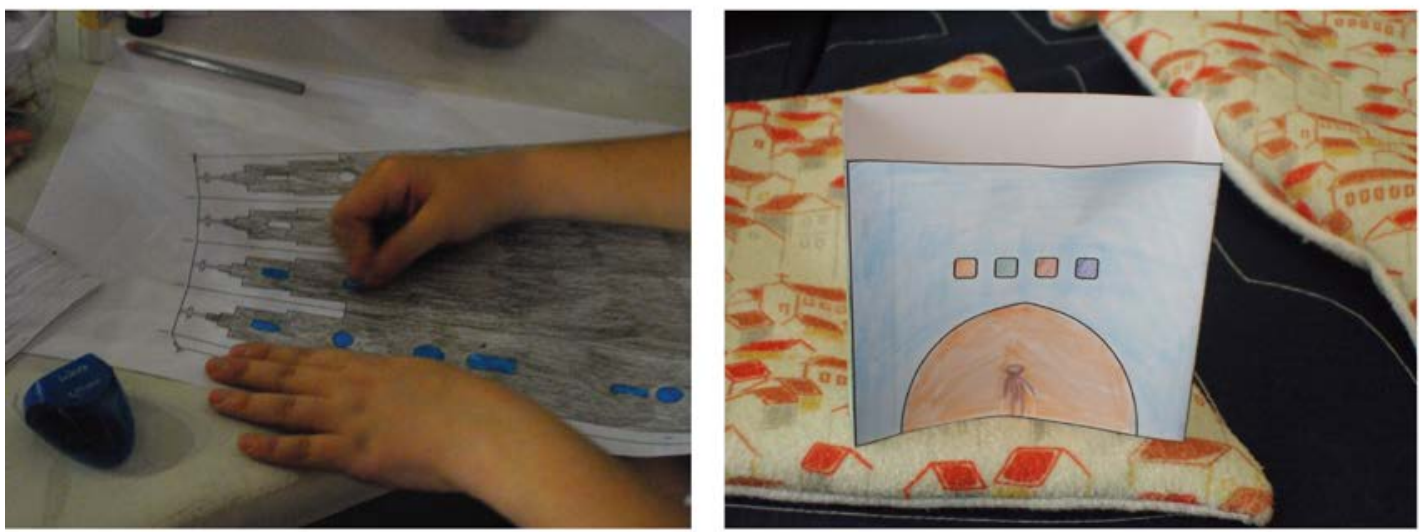

Figuras 6 e 7: Customização dos monumentos pelas crianças.

Fotos: Eduardo Massa e Vânia Cunha

\subsection{Design como processo}

Nos dois casos citados acima, o resultado final foi um objeto - os módulos em Serralves, e o mapa tridimensional do Porto, na Casa do Infante. No entanto, em nenhum momento a finalidade das ações foi a materialização destes. O que se pretendia era uma resposta a uma situação: como comunicar-se com um determinado grupo, em ambos os casos, as crianças, embora em faixas etárias diferentes nas duas situações. Os objetos serviram apenas como mediadores da relação entre este público e os museus. Dito isto, nesta interação reside uma das possíveis contribuições do design para estas instituições.

Podemos traçar um paralelo com o que Buchanan chama de "terceira área do design" 5 . Para o autor, o aspecto mais interessante desta terceira área é a interação, seja ela de qualquer ordem, entre pessoas e pessoas, ou entre pessoas e objetos. E o designer pode produzir ou planejar coisas que apoiem estas relações. (Buchanan, 1992)

Voltando ao projeto concebido para a Casa do Infante, todo ele foi desenvolvido para intermediar interações, entre os participantes e o museu, a cidade, e entre eles próprios. O objeto/jogo desempenhou o papel de mediador, mas o relevante não é ele próprio, ele em si, mas sim a experiência que ele propicia. 0 projeto foi uma resposta a uma necessidade de aproximação com o público infantil planejada para este caso específico, não é necessariamente uma resposta para outras instituições culturais. Cabe salientar também que não era a única "resposta" possível. No caso o papel do designer é avaliar a situação e propor soluções, respostas, que vão variar de acordo com o contexto.

No artigo "Definition of design" o também professor William Miller, diz que apesar de em inglês se pensar no termo design tanto como substantivo quanto como

\footnotetext{
${ }^{5}$ Segundo o autor, a comunicação visual seria a primeira área do design; a seguinte seria a produção de objetos; a terceira tem em conta processos e atividades; e ainda teria uma quarta associada a sistemas e ambientes. (Buchanan, 1992, p. 9-10)
} 
verbo, sua ideia é se concentrar no último sentido já que seu intuito é ressaltar o design como um processo. (Miller, 2004).

(...) design não é "produto", "produto" é, sim, a saída do design. Aquilo que foi criado não é um "design", é o que é (uma casa, um automóvel, um computador, um programa de cuidados de saúde, uma peça de música, etc), é uma "entidade" em si mesmo. O design é o processo usado para criar essa entidade. (Miller, 2004).

O discurso de Miller serve para ressaltar que, independente da produção material, o design pode contribuir com os museus como um processo de criação de interação para com o público, ou seja, o design com sua abordagem reflexiva pode trazer novas soluções para novos desafios.

\section{CONCLUSÃO}

Recuperando o pensamento dos situacionistas, anteriormente apresentado no tópico 2.1, percebemos no convite à participação ativa do público um viés inovador para se apropriar não só da cidade como da arte. O estar "à deriva" é de certa forma estar aberto às possibilidades vislumbradas durante o percurso de acordo com o momento e o contexto, características essas também presentes nos processos criativos. O paralelo desta abordagem com o design traz à tona a reflexão sobre a liberdade processual da área, como exposto nos itens 2.2 e 2.3 do presente artigo.

A ideia de associar o movimento situacionista ao design e, mais precisamente com aquele presente no museu, tem por finalidade destacar as diversas articulações possíveis. A associação do campo com o pensamento situacionista não foi por acaso. A pretensão de pensar o design "à deriva" relaciona-se a pensar criativamente, em que as condições do caminho e as escolhas feitas traçam um determinado percurso.

No âmbito da relação Design e Museologia, mais importante do que pensar o design como a materialização de um objeto, é refletir sobre uma atitude, sobre um processo de escolhas a partir de um contexto específico, sobre uma articulação entre diferentes campos de saber. É estar aberto a uma ação conjunta e de diálogo efetivo.

Quanto aos museus, apesar de termos abordado dois exemplos de colaboração do design atuando nestas instituições, verificamos que esforços para desenvolver estratégias de comunicação que atendam aos mais variados públicos, ainda são um grande desafio. Afinal, além de elaborar atividades que aproximem um público que normalmente não tem o hábito de frequentar instituições culturais é necessário manter o entusiasmo do público assíduo.

Os casos práticos aqui mostrados servem como exemplos de atuação possível para lidar com novos desafios nestas instituições, e devem ser encarados não como soluções fechadas e capazes de serem reproduzidas. Afinal, lidamos com situações complexas, que podem variar de acordo com o contexto. De acordo com o caminho percorrido, novas paisagens são vislumbradas.

Os exemplos relatados nos fazem inferir que a inclusão do design pode ser de grande valia na elaboração de práticas que promovam uma democratização de acesso aos museus e que sejam capazes de fomentar experiências significativas. A partir do paralelo feito com os situacionistas, entendemos que o designer pode ser visto como um propositor de situações, situações estas que convidem o público à reflexão, que levem em conta suas expectativas e que busquem um diálogo mais afetivo. 


\section{REFERÊNCIAS}

ALEXANDRE, Rosana Ferreira. Porto através do jogo: Uma construção lúdica para o Museu Casa do Infante. Dissertação. Faculdade de Belas Artes da Universidade do Porto, 2009.

BUCHANAN, Richard. Wicked Problems in Design Thinking. In: Design Issues. v. 8, n. 2, p. 5-21. Massachusetts: MIT press, 1992.

CANÔNICO, Marco Aurélio; CYPRIANO, Fabio. Leia a íntegra da entrevista com Paulo Herkenhoff, diretor do Museu de Arte do Rio. In: Ilustrada, Folha de São Paulo. 28/02/2013. Disponível em: http://www1.folha.uol.com.br/ilustrada/2013/02/ 1237631-leia-a-integra-da-entrevista-com-paulo-herkenhoff-diretor-do-museu-dearte-do-rio.shtml. Acesso em: 25/05/2014.

COUTO, Rita Maria de Souza. O Movimento Interdisciplinar de Designers Brasileiros em Busca de Educação Avançada. 1997. Tese (doutorado). Departamento de Educação da Pontifícia Universidade Católica do Rio de Janeiro.

CROSS, Nigel. Designerly Ways of Knowing: Design Discipline Versus Design Science. In: Design Issues. v. 17, n.3, p. 49-55. Massachusetts: MIT press, 2001.

DEBORD, Guy. A Sociedade do espetáculo. Tradução: Francisco Alves, Afonso Monteiro. Lisboa: Afrodite, 1972.

JAPIASSÚ, Hilton. Questões epistemológicas. Rio de Janeiro: Imago, 1981.

LARA FILHO, D. (2012). O museu no século XXI ou o museu do século XXI. Fórum Permanente: Museus de Arte; entre o público e o privado, v. -, p. -, 2005. Disponível em: http://www.forumpermanente.org/revista/edicao-0/textos. Acesso em:

07/04/2016.

MACEDO, Lino de; PETTY, Ana Lúcia Sícoli; PASSOS, Norimar Christe. Os jogos e o lúdico na aprendizagem escolar. Porto Alegre: Artmed, 2005.

MILLER, William R. Definition of design. Publicado em: 2 nov. 2004. Disponível em: http://www.wrmdesign.com/Philosophy/Documents/DefinitionDesign.htm. Acesso em: 12/11/2013.

POULOT, Dominique. Museu e Museologia. Tradução: Guilherme João de Freitas Teixeira. Belo Horizonte: Autêntica, 2013.

RITTEL , H.; WEBER , M. Dilemmas in a general theory of planning. In: Policy Sciences v. 4. Amsterdam: Elsevier, 1973. 